\title{
P03-10-6 Poster session
}

\section{Evaluation of Anti-inflammatory and Analgesic properties of Mitragyna inermis extract}

\author{
Monday M. Onakpa, Chiazor G. Ezugwu, Julius O. Ode, Peter O. Ajagbonna \\ Department of Pharmacology and Toxicology, Faculty of Veterinary Medicine, University of Abuja, PMB 117, Abuja. \\ Nigeria
}

Background: Inflammation is a pervasive phenomenon elicited by the body in response to obnoxious stimuli as a protective measure. If sustained inflammation can lead to several diseases including cancer; therefore the necessity to neutralize inflammation is paramount. Mitragyna inermis $\mathrm{O}$. Kuntze is a medicinal plant traditionally used as a medicine in Ayurveda and other folk systems of medicine to manage several diseases including malaria and other feverish conditions, diarrhea, cough, muscular pains and as anthelminthes. Despite these facts there is paucity of scientific information on its anti-inflammatory and analgesic properties. The present study evaluates the anti-inflammatory and analgesic activities of $\mathrm{M}$. inermis in Wistar rats.

Methods: The anti-inflammatory and analgesic activities of M. inermis were studied in Wistar rats by different methods. The hot plate, acetic acid, and tail immersion tests were used to evaluate the analgesic activity whereas xylene-induced ear edema and formalin induced paw edema tests were used to study the anti-inflammatory activity of M. inermis.

Results: The administration of 100,200 and $400 \mathrm{mg} / \mathrm{kg}$ to rats reduced pain and inflammation in a dose-dependent manner indicating that $\mathrm{M}$. inermis possesses analgesic and anti-inflammatory activities. The maximum analgesic and antiinflammatory activities were observed in groups receiving $400 \mathrm{mg} / \mathrm{kg}$ of M. inermis extract.

Conclusion: This study indicates that M. inermis possesses both anti-inflammatory and analgesic activities and it may be useful in the development of an anti-inflammatory and/or analgesic agent; our study also validates the traditional use of Mitragyna inermis. 